\title{
Electrochemical Behavior of Carbon Fiber - Coupled Steel in Concrete Environment
}

\author{
Chun Bai ${ }^{1,2,3,4}$, Shuxian Liu ${ }^{1}$, Fenghai Ma ${ }^{2}$, Shasha Lu ${ }^{1, *}$, Junmei Wang ${ }^{3,4}$, Shaodong Liu ${ }^{1}$ \\ ${ }^{1}$ College of Civil Engineering, Liaoning Technical University, Fuxin, Liaoning, 123000, P.R. China \\ ${ }^{2}$ College of Architecture and Civil Engineering Dalian University, Dalian, Liaoning, 116622, P.R. \\ China \\ ${ }^{3}$ College of Civil Engineering, Xuchang University, Xuchang, Henan, 461000, P.R. China \\ ${ }^{4}$ College of Architecture and Civil Engineering, Shangqiu University, Shangqiu Henan, 476000, P.R. \\ China \\ *E-mail: bianqiao82536967@163.com
}

doi: $10.20964 / 2020.05 .81$

Received: 1 January 2019 / Accepted: 17 February 2020 / Published: 10 April 2020

\begin{abstract}
As a new structural building material, carbon fiber-reinforced concrete has very good flexural strength, wear resistance and impermeability. However, because carbon fiber is a good conductor, the durability of reinforced concrete structures may be affected if it comes into contact with steel bars in the concrete, thus allowing the formation of a galvanic couple. In this paper, electrochemical tests and corrosion weightlessness experiments were carried out in a pore fluid of concrete with a $\mathrm{pH}$ of 12.5 . The results showed that when carbon fiber was coupled with carbon steel, the double layer capacitance $\left(\mathrm{C}_{\mathrm{dl}}\right)$ increased and the charge transfer resistance $\left(\mathrm{R}_{\mathrm{ct}}\right)$ decreased. The thickness of the passivation film decreased, and the protective performance of the passivation film on the carbon steel decreased. Moreover, the corrosion potential of the carbon steel increased, the corrosion current density increased, and the corrosion rate of the carbon steel increased. An XPS analysis confirmed the results of the electrochemical experiments. After carbon fiber coupling, the ratio of $\mathrm{Fe}^{3+} / \mathrm{Fe}^{2+}$ on the surface of the carbon steel decreased, and the stability of the passive film on the surface of the carbon steel decreased. Although coupling with carbon fiber had a negative effect on the passivation of the carbon steel, the surface of the carbon steel could still maintain good passivation in a chloride-free simulated pore fluid environment.
\end{abstract}

Keywords: Concrete pore fluid, Cement mortar, Reinforcement, Carbon fiber, $\mathrm{pH}$ value, Electrochemical analysis 
(C) 2020 The Authors. Published by ESG (www.electrochemsci.org). This article is an open access article distributed under the terms and conditions of the Creative Commons Attribution license (http://creativecommons.org/licenses/by/4.0/). 